\title{
Review: \\ Diversity Now! \\ 2020 with Becca \\ McCharen-Tran, \\ CHROMAT
}

By Ryan Chantree

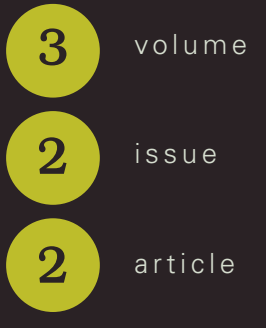

KEYWORDS:

INCLUSIVITY

\section{DIVERSITY}

\section{CHROMAT}

\section{FASHION DESIGN}

REVIEW

\section{Abstract}

For the eighth iteration of the Diversity Now! lecture series, the Research Centre for

Fashion \& Systemic Change invited Becca McCharen-Tran to Ryerson University to speak about her experiences founding the fashion label Chromat. Initially educated in architecture from the University of Virginia, McCharen-Tran has become a well-known vanguard for inclusivity in fashion, making her signature queer futuristic sportswear for sizes XS-4XL. She was awarded runner-up in the CFDA/Vogue fashion fund in 2017, made Forbes' 30 Under 30 list for "People Who are Reinventing the World in 2014," and her clothing has been worn by celebrities like Beyoncé and Madonna. In her talk, McCharen-Tran offered candid advice on establishing a label with inclusivity at the core of its DNA, the key take-away being that inclusivity requires work and the willingness to prioritize the needs of those most often excluded. 


\section{INTRODUCTION}

The annual Diversity Now! lecture, hosted by the Research Centre for Fashion \& Systemic Change at Ryerson University, always promises an enlightening discussion with an industry leader on how fashion can be used to advocate for diversity and affect social change. The 2020 iteration invited the much-lauded Becca McCharen-Tran, founder of the brand Chromat, to discuss how she built her label to do just that (Figure 1).

\section{In a fashion industry predominated by promises of an ethical future, McCharen-Tran stands as part of the growing group of designers actively making the pathway there.}

"Inclusivity" and "diversity" must be more than simply fashion's latest plat du jour and should involve a willingness to reconfigure the foundations of how we operate in the fashion industry and the world at large. Perhaps one of the most important takeaways from McCharen-Tran's talk is that in order to enact these changes they need to be a priority at all levels of one's operations. As McCharen-Tran says, "inclusivity means nothing if it's surface level" (Diversity Now! 2020), and Chromat stands as a testament to this thinking.

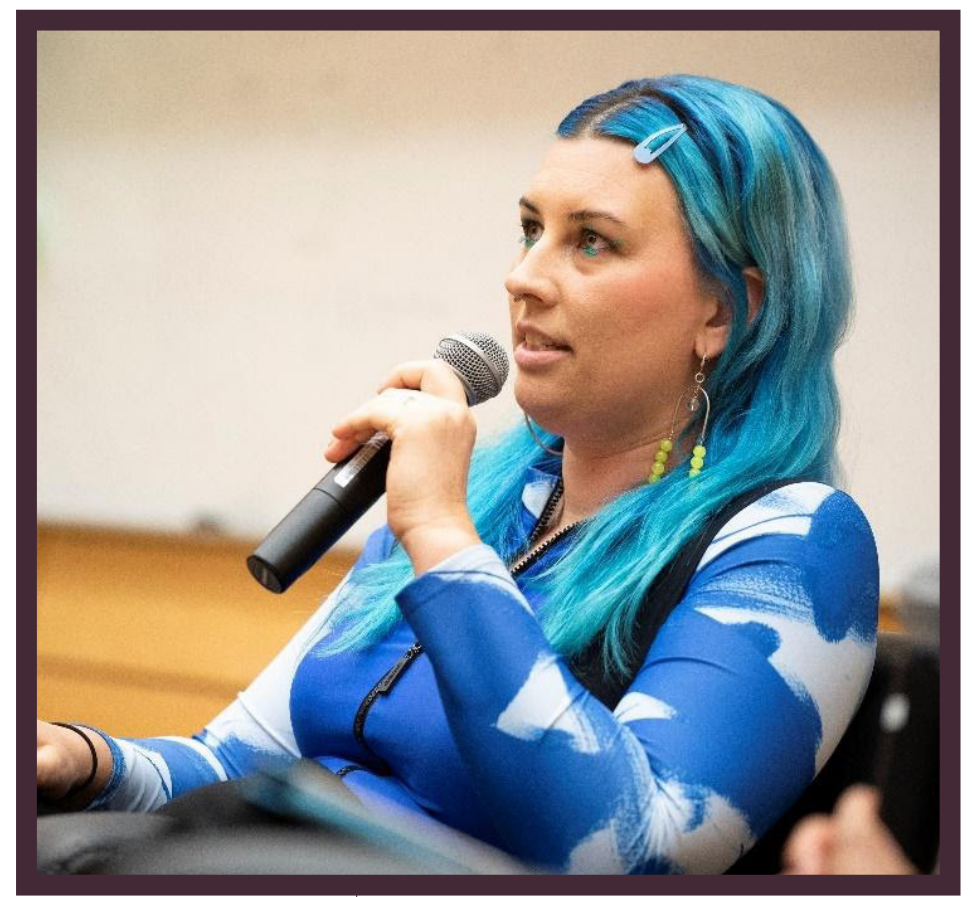

FIGURE 1 Tagabing, K. (March 10 2020) [Becca McCharen-Tran speaking at Diversity Now!], Ryerson University, Toronto, Ontario. 


\section{WHO IS CHROMAT?}

McCharen-Tran founded Chromat in 2010, and although not trained as a fashion designer, her education from the University of Virginia's School of Architecture is clearly seen in the cagey, scaffolding garments that are a mainstay of the brand. Layered underneath these gravity-defying frames are the equally engineered neon sportswear pieces that dart around the models' figures with dynamic straps, cutouts, and graphics. Styled with anything from strappy heels to their latest collaboration with Reebok, the pieces come together to manifest a vision of queer athletica. Chromat's latest runway show at the time of lecture, Autumn/Winter 2020, went so far as to take place in a gym with the models profiling the clothes by actually exercising in them. Juxtaposing activewear with active spaces by most other brands would perhaps be expected, however the casting of their models pushes the aesthetics of the show into a crucial political message. Gyms and other athletic spaces are often potent sites of normative violence against marginalized people (Barry,2018), and while Chromat is no stranger to a diverse runway, with their models consistently encompassing a diverse range of ages, abilities, sizes, genders, and ethnicities, the Autumn/Winter 2020 collection explicitly advocated against the biopolitics of who gets to occupy which spaces and participate in which events (Chromat, 2020). They create a space where all bodies are present and celebrated, effectively manifesting their vision for a queer future.

\section{The image of the slim, white, able-bodied, young figure runs rampant within fashion and sports media, and Chromat uses a design language that is usually only seen on those who embody these normative beauty ideals to construct a world where everyone gets to exist and flourish.}




\section{INCLUSIVITY IN A BUSINESS MODEL}

While Chromat's design aesthetic captures the inclusive spirit of the brand, that spirit carries throughout the entirety of its operations, extending to the decision makers behind the scenes. As McCharen-Tran emphasizes, "Chromat has been built by so many people, not just me" (Diversity Now! 2020), and having a plethora of voices to contribute to the design process helps to ensure a foundation that supports their ideals. This approach has also been demonstrated in their fit testing events where up to five hundred people have been invited to test the designs they were working on (Chromat, 2020). While fit testing is a standard process for fashion design, it is not usually so extensive, and most designers will try to use models who already adhere to their standard sizing.

\section{By investing energy into actively engaging their consumers, Chromat can assess and test their design ideas to accommodate a far broader array of bodies and sensibilities.}

As such, they have been able to expand their sizing up to a $4 \mathrm{XL}$ and ensure that these designs continue to be wearable at those sizes. Additionally, they shifted from a wholesale to a direct-to-consumer model to substantially lower the price of their pieces after consultations with their customers (Chromat, 2019). While it is worth noting that $\$ 100-\$ 200$ for a swimsuit set is still inaccessible for many people, this shows that Chromat is willing to engage their consumers and act on the feedback they receive, even if it means shifting their entire distribution strategy. 


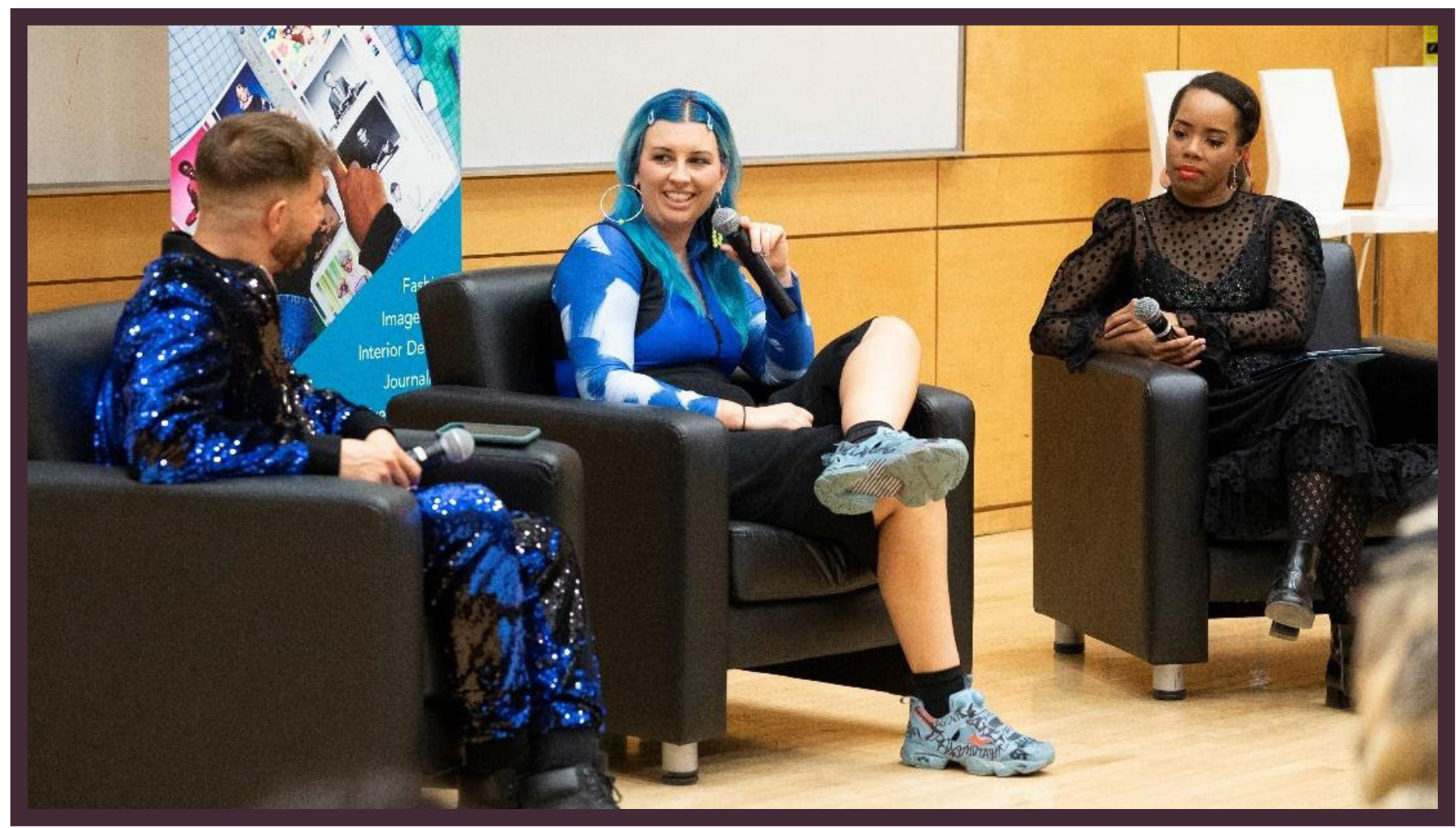

FIGURE 2 Tagabing, K. (March 10 2020) Dr. Ben Barry, Kimberly Jenkins, and Becca McCharen-Tran speaking at Diversity Now!, Ryerson University, Toronto, Ontario.

\section{PUTTING IDEALS INTO ACTION}

While conversations about inclusivity are certainly important, oftentimes they can be limited to the realm of utopia, remaining a distant goal we will one day reach. McCharen-Tran's lecture stands out from this discourse that can too easily be mired in theory without practice, as she offered her experiences candidly to the fashion students in attendance. During the Question \& Answer period with Dr. Ben Barry and Kimberly Jenkins (Figure 2), McCharen-Tran was able to elucidate upon how Chromat has grown into the brand it is today. While
Chromat has been a label interested in advocating for inclusion since its conception, much of the work they have done has been a process over the course of years. For instance, expanding their size range required a plussize mannequin, time to make the new size 20 croquette, and the aforementioned extensive consumer research. As such, an emergent designer may not have access to the resources necessary to follow suit. However, rather than rendering size inclusivity as impossible, McCharen-Tran suggests that it is instead a matter of priorities. Making a brand that works for those who are typically ignored by the fashion industry requires work, and one may have to reassess what they are producing and if their resources can be reallocated to address the needs of those consumers. While that work may not have a simple or obvious solution, being willing to prioritize finding that solution over repeating the status quo is key to enacting change. Like McCharen-Tran says, "We have the responsibility to create the world we want to see, and we have the power" (Diversity Now!, 2020). 
To watch McCharen-Tran's lecture and conversation with Dr. Ben Barry and Dr. Kimberly Jenkins in its entirety online, you can access the Ryerson University Ryecast here. This year's ninth annual Diversity NOW! lecture will be an interactive workshop with Legin Knits taking place this April 2021: https://www. leginknits.com/. Follow the Centre for Fashion Diversity and Social Change on Twitter at @ryersonFSC and on Instagram at @fashionsystemicchange and Fashion Studies on Twitter and Instagram @ FashionStudies for more details on this year's Diversity NOW! lecture.

Barry, B. "Enclothed Knowledge: The Fashion Show as a Method of Dissemination in Arts-Informed Research.” Fashion Studies 1(1), 2018, pp. 1-43, https://doi. org/10.38055/FS010104.

McCharen-Tran, B. (2020, Mar. 10). Diversity Now! 2020 with Becca McCharen-Tran, CHROMAT [Lecture]. Diversity Now!, Ryerson University. Retrieved from: https://ryecast.ryerson.ca/31/Watch/16422.aspx.

Chromat. (2019, Sep. 2). WE'VE GOT A BIG ANNOUNCEMENT. Chromat. https://chromat.co/blogs/news/dtc.

Chromat. (2020, Jan. 14). Chromat Fit Tests. Chromat. https://chromat.co/blogs/news/ fit-test.

Chromat. (2020, Feb. 10). Chromat 2020 NYFW Training Session. Chromat. https:// chromat.co/blogs/news/chromat2020. 


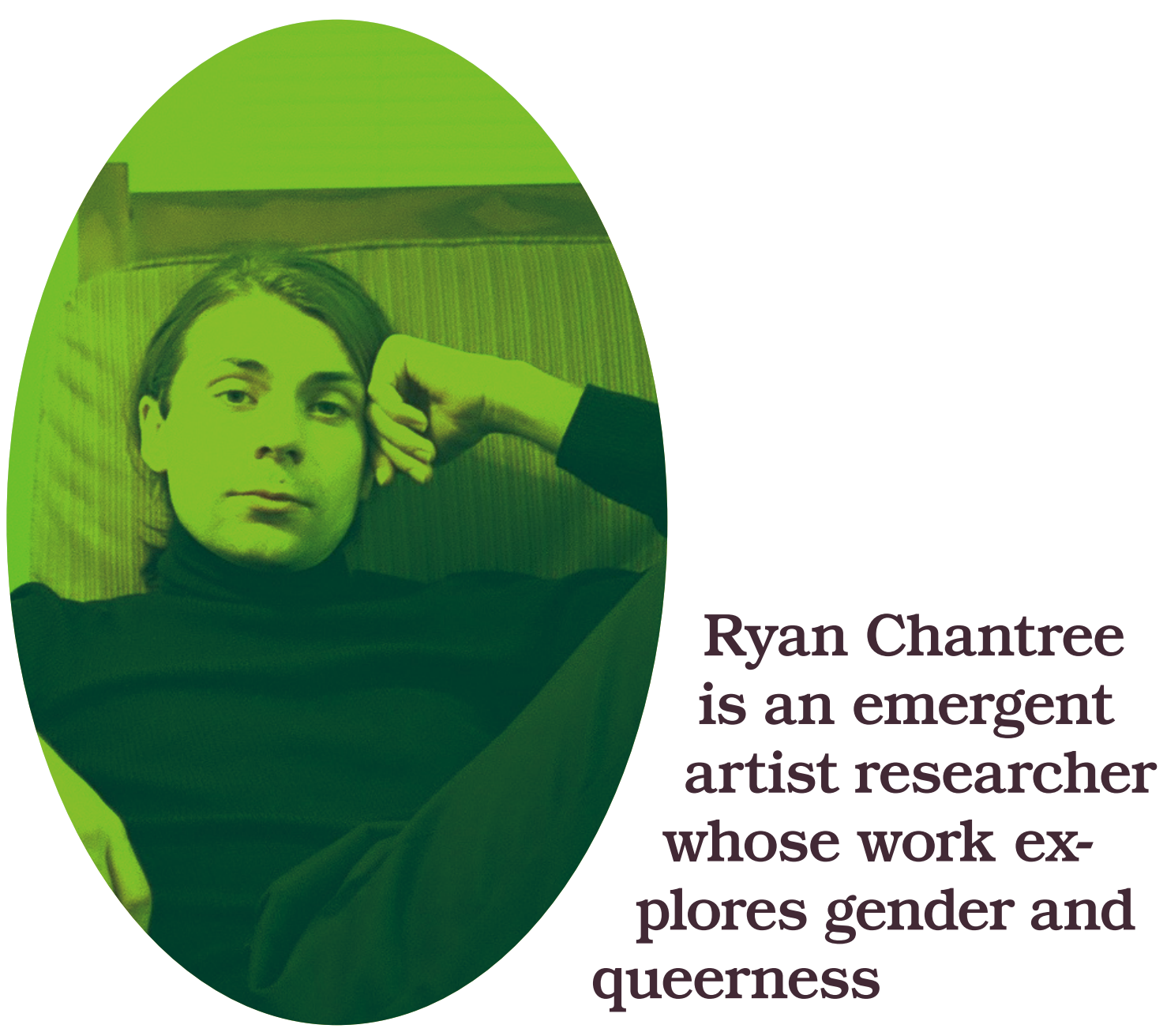

through experimental processes rooted in queer, feminist, and fashion theory. They hold an MA in Fashion from Ryerson University and a BFA from Emily Carr University of Art and Design.

ARTICLE CITATION

Chantree, Ryan. "Review: Diversity Now! 2020 with Becca McCharen-Tran, CHROMAT." Fashion Studies, vol. 3, no. 2, 2021, pp. 1-8, https://www. fashionstudies.ca/diversity-now-with-becca-mccharen-tran-chromat, https://doi.org/10.38055/FS030202. 


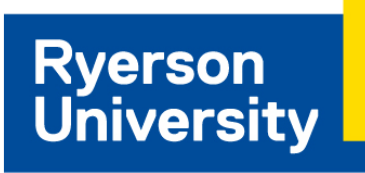

Fashion

Faculty of Communication

\& Design

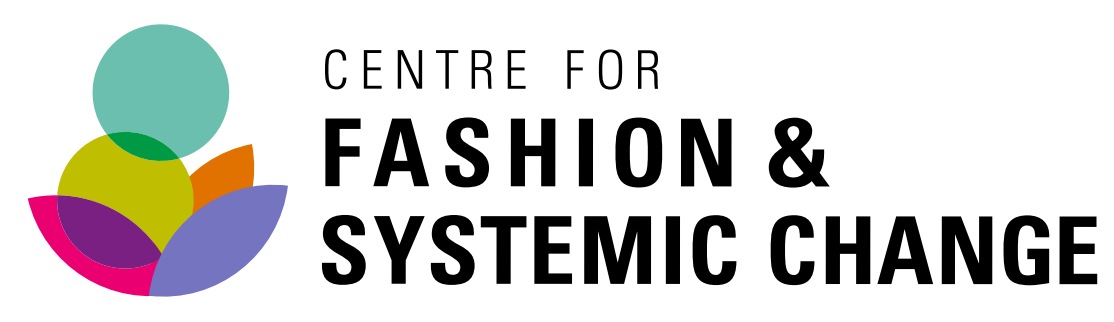

Frows $\mathrm{SH} / \mathrm{ON}$

ISSN 2371-3453

Copyright (C) 2021 Fashion Studies - All Rights Reserved

Creative Commons Attribution-NonCommercial-NoDerivatives 4.0 International (CC BYNC-ND 4.0) license (see: https://creativecommons.org/licenses/by-nc-nd/4.0/) 